\title{
Enhance Maize (Zea mays L.) Tolerance to Abiotic Stress Through the Genetic Transformation with Anthranilate Synthase (ASA2 Gene) Using Particle Bombardment
}

\author{
Karim Mohamed Beltagy', Manal Moustafa Abdel-Rahman', Hanaa Mahdy Abouzied ${ }^{2, *}$, \\ Samia Ahmed Madkour ${ }^{1}$ \\ ${ }^{1}$ Plant Pathology Department (Genetic Branch), Faculty of Agriculture, Damanhour University, Damanhour, Egypt \\ ${ }^{2}$ Agronomy Department, Faculty of Agriculture, Damanhour University, Damanhour, Egypt

\section{Email address:} \\ beltagy.kareem@yahoo.com (K. M. Beltagy),manal_moustafa2000@yahoo.com (M. M. Abdel-Rahman), \\ hmmahdy@yahoo.com (H. M. Abouzied),samiamadkour@yahoo.co.uk (S.A. Madkour) \\ ${ }^{*}$ Corresponding author
}

\section{To cite this article:}

Karim Mohamed Beltagy, Manal Moustafa Abdel-Rahman, Hanaa Mahdy Abouzied, Samia Ahmed Madkour. Enhance Maize (Zea mays L.) Tolerance to Abiotic Stress Through the Genetic Transformation with Anthranilate Synthase (ASA2 Gene) Using Particle Bombardment. American Journal of Bioscience and Bioengineering. Vol. 7, No. 2, 2019, pp. 28-33. doi: 10.11648/j.bio.20190702.11

Received: March 4, 2019; Accepted: March 19, 2019; Published: May 7, 2019

\begin{abstract}
The agricultural plans in Egypt aim to increase maize production and yield to reduce the importation and to meet the country's need from maize. Currently the crop production is affected by the climatic changes which rise the abiotic and biotic stresses problems. In an attempt to raise the tryptophan level in maize, particle bombardment technique was used with two hybrids maize, namely Sc168 and Sc10. The results of this study showed that both hybrids were transformed efficiently and showed increased levels of tryptophan in the two hybrids. The double shot 1100 psi was higher effective than single shot. It can be concluded that levels of tryptophan increased clearly in the two hybrids which is considered an indicator for ASA2 successful expressing as compared to control. The present study established effective tissue culture protocol for maize hybrids suitable for gene transformation which may used in maize improvement programs in the future.
\end{abstract}

Keywords: Maize, Biotic Stress, Anthranilate Synthase, Gus Assay, Particle Bombardment

\section{Introduction}

Maize, wheat and rice are the most important cereal crops, their grains considered as the main source of carbohydrates across the world [1]. Sustainable agriculture in Egypt is faced by many constraints like, the climatic changes, waste irrigation water in large quantities, especially in the old cultivated lands, the rise in the level of ground water and the increase in the salinity of agricultural land, which causes the productivity of these lands to decrease [2].

Maize improvement in breeding programs depend on the use of specific molecular markers of important genes govern important traits and genetic engineering of major genes [3]. Many agronomic traits of maize can be improve by introducing genes to its genome. Transformation of monocot crops like cereal was successfully made after the progress of the particle bombardment technology that uses high speed particles to deliver DNA directly into the cell nucleus [4].

Two popular methods are known to be used for maize genetic transformation Agrobacterium mediated transformation and particle bombardment [5]. Genetically transformed maize have already been made with different traits involving tolerance and resistance to various biotic and abiotic stresses environmental factors $[6,7]$.

Tryptophan is a natural amino acid has a vital role in plant growth and development, it acts as, ion transport regulator, an osmolyte, controls stomatal opening, initiates the formation of alkaloids and serotonin and detoxify harmful effects of heavy metals [8-11].

Rice and Arabidopsis exhibit abiotic stress-induced regulation of the enzymes of tryptophan biosynthesis pathway, namely anthranilate synthase and tryptophan synthase [12, 13]. The activity of anthranilate synthase and accumulation of 
tryptophan-derived metabolites has been observed in the leaves of rice plants in response to biotic stress $[12,13]$. The objective of this work was to enhance maize tolerance to abiotic stress through the genetic transformation with Anthranilate synthase (ASA2 gene) using particle bombardment.

\section{Material and Methods}

\subsection{Plant Materials}

Two maize hybrids (Zea mays L.) namely, Sc168 and Sc10 (Agriculture research center) were used in this study. Ears were harvested between 12-14 days after pollination with 1.2$1.8 \mathrm{~mm}$ embryos size. The ears were surface sterilized for 5 $\min$ in $70 \%$ ethanol then for $20 \mathrm{~min}$ in Clorox $10 \%$. This was followed by three times rinse in sterile distilled water. Immature embryos were aseptically isolated by cutting the tips of the kernels with a scalpel without touching the embryo.

\subsection{Initiation Medium}

The embryos were placed on medium N6 (14).
Supplemented with N6 salts, 3\% sucrose, $2.76 \mathrm{~g}$ proline, 2 $\mathrm{mg} / 1$ 2,4-D, $0.1 \mathrm{mg} / \mathrm{l}$ Casein hydrolysate, $10 \mathrm{ml}$ N6 vitamins, 20 g/l Poly Ethylene Glycol (PEG) and 8g/1 Agar. The media was adjusted to $\mathrm{pH} 5.8$. Silver nitrate $25 \mu \mathrm{M}$ was added after autoclaving. Twenty embryos were placed in each Petri. A randomized complete block design with forty one replicates was used. Cultures were incubated in the dark at $28^{\circ} \mathrm{C}$. Percentage of immature embryos forming primary callus was recorded two weeks after culture. The developing callus was sub-cultured after 21 days into the callus maintenance medium as for callus induction medium. Two types of calluses were grown (embryogenic, non-embryogenic).

\subsection{Plasmid Structure}

The plasmid used in this work, pC2ASA2-NOS-ASB 16.6 $\mathrm{kb}$ (MTA, Illinois University), (Figure 1) contains a selectable marker (ASA2 a \& $\beta$ ) the coding region of kanamycin, gusA, under control of the cauliflower mosaic virus (CAMV). ANOS polyA (nopaline synthase) terminator sequence.

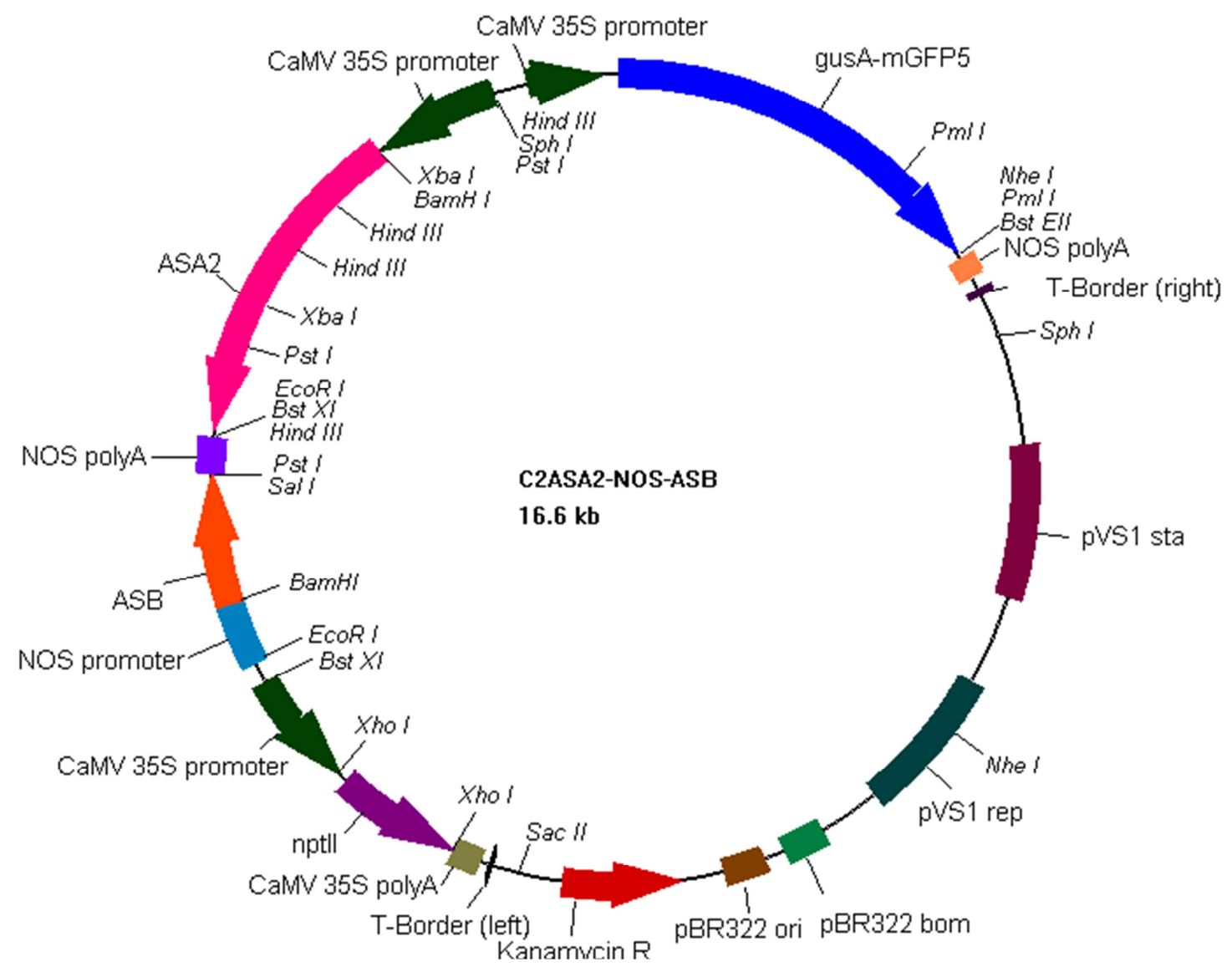

Figure 1. Schematic drawing of the plasmid C2ASA2-NOS-ASB. The plasmid $16.6 \mathrm{~kb}$ consists of ASA2, ASB, CaMV35S: cauliflower mosaic virus $35 \mathrm{~S}$ promoter and 3 'NOS: the polyadenylation signal of nopaline synthase.

\subsection{Maize Transformation and Regeneration}

Friable callus was used for particle bombardment. Callus was transferred to osmoticum medium (N6 medium +36.4 $\mathrm{g} / \mathrm{L}$ sorbitol and $36.4 \mathrm{~g} / \mathrm{L}$ mannitol) for 4 hours prior to bombardment. The gold particles (Bio-Rad) $(1 \mu \mathrm{g})$ was used to precipitate DNA onto the microparticles $1 \mu \mathrm{L}$ plasmid DNA (stock $1 \mu \mathrm{g} \mu \mathrm{L}^{-1}$ ). Then, $220 \mu \mathrm{L}$ (stock $2.5 \mathrm{M}$ ) and $50 \mu \mathrm{L}$ spermidine (stock $0.1 \mathrm{M}$ ) were added and homogenized. The mixture was kept on ice for $5 \mathrm{~min}$ and vortexed for 5 min, micro centrifuged at $5000 \mathrm{rpm}$ for $1 \mathrm{~min}$, rinsed 
carefully with $250 \mu \mathrm{l}$ of ethanol and suspended in $40 \mu \mathrm{L}$ $100 \%$ ethanol. $10 \mu \mathrm{l}$ of the DNA -coated particles were pipetted onto each macrocarrier (washed in absolute EtOH, dried before uses). Bombardments were performed on Petri dishes containing friable callus clump in the middle. Different treatments were designed to test the pressure of the accelerating helium pulse 1100 psi single and double shout)..

\subsection{Histochemical Detection of GUS Activity}

After bombardment calli were incubated for $24 \mathrm{~h}-48 \mathrm{~h}$ in the dark at $28^{\circ} \mathrm{C}$. The best substrate available for histochemical localization of $\beta$-glucuronidase activity in calli is 5-bromo-4chloro-3- indolyl glucuronide (X-Gluc). Some samples of tissue and cells were put in wells of microtiter plate. X-Gluc solution were added which contains $380 \mu \mathrm{l} \mathrm{IM} \mathrm{Na}, 620 \mu \mathrm{l}$ $1 \mathrm{M} \mathrm{NaH}{ }_{2} \mathrm{PO}, 200 \mu \mathrm{l} 0.5 \mathrm{mM}$ EDTA, $1000 \mu \mathrm{l} 0.5 \mathrm{mM} \mathrm{K}$ ferricyanid 16) e, $1000 \mu 10.5 \mathrm{mM} \mathrm{K}$ ferrocyanide, X-Gluc (10 mg in $40 \mu \mathrm{l}$ of DMF) and $6760 \mu \mathrm{l}$ water. Vacuum for 5$10 \mathrm{~min}$, avoid air bubbles and floating samples, incubate on $37^{\circ} \mathrm{C}$ overnight, sealed with parafilm and then photographed.

\subsection{Selection and Regeneration of Transformants}

After bombardment, explants were kept in dark at $28^{\circ} \mathrm{C}$ for 7-10 days then transferred to selection medium with inhibitor 6- methyl D-L-tryptophan with concentration $100 \mu \mathrm{M}$. After three cycles of selection, transformed calluses were transferred for regeneration medium. The surviving callus was transferred to regeneration medium MS medium [15]. Supplemented with $1 \mathrm{ml} / \mathrm{L}$ (1000X) MS vitamin stock, 100mg/Lmyo-inositol, $60 \mathrm{~g} /$ Sucrose, $3 \mathrm{~g} / \mathrm{L}$ gelrite, $\mathrm{pH} 5.8$, after autoclaving $100 \mathrm{mg} / \mathrm{mL}$ of $6 \mathrm{MT}$ was added. The calluses were incubated for 2 weeks at $25^{\circ} \mathrm{C}$ in the dark. After 2 weeks, transformed green calluses were transferred to the light on Regeneration medium (II) which is the same for MSI except MSII supplemented with $30 \mathrm{~g} / \mathrm{L}$ sucrose.

\subsection{HPLC Analysis}

Tissue samples were frozen in liquid nitrogen and stored at $-70^{\circ} \mathrm{C}$ until analyzed. Samples were ground frozen into a coarse powder and approximately $100 \mathrm{mg}$ of tissue was homogenized with $0.1 \mathrm{n} \mathrm{HCl}\left(2 \mathrm{~mL} \mathrm{~g}^{-1}\right.$ tissue $)$ in a microfuge tube using a plastic pellet pestle (Kontes Glass). The sample was then frozen in liquid nitrogen, thawed, and microfuged to sediment debris. A portion of the supernatant was deproteinated using an Ultra Free-MC (10,000) filter unit (Millipore, Bedford, MA) according to the manufacturer's directions. The filtrate was further diluted with $0.1 \mathrm{n} \mathrm{HCl}$ as necessary (1:10 for most samples) and $10 \mu \mathrm{L}$ was analyzed by HPLC by methods similar to that of Berardino et al [16], using a 250- $\times 4.6-\mathrm{mm}$ Adsorbosil C18 column (Alltech Associates, Deerfield, IL), an isocratic buffer system $(85 \%[\mathrm{v} / \mathrm{v}]: 140$ mmsodium acetate, $17 \mathrm{~mm}$ triethylamine, adjusted to $\mathrm{pH} 5.05$ using phosphoric acid, and

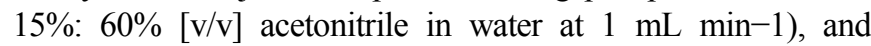
fluorescence detection (Kratos FS970; excitation, $215 \mathrm{~nm}$; emission, band pass filter $>375 \mathrm{~nm}$ ). All free amino acids were measured as described in Brotherton et al. [17].

\subsection{Statistical Analysis}

Data for callus formation on the initiation were statistically analyzed using the analysis of variance procedures by SAS 9.2 (SAS v9.2; Cary, NC, USA) for a randomized complete design as follows:

$$
\mathrm{Yij}=\mu+\tau+\varepsilon
$$

Where: Yij is the jth observation of the ith treatment, $\mu$ is the population mean, $i \tau$ is the treatment effect of the ith treatment, and ij $\varepsilon$ is the random error.

\section{Results and Discussion}

\subsection{Callus Formation on Induction Medium}

This study is carried out to enhance maize abiotic stress tolerance by taking the advantage of modern biotechnology tools such as genetic engineering and plant tissue culture. Analysis of variances for the alive calli revealed that there were significant differences between the two hybrids $\mathrm{p} \leq 0.01$, while, there were non-significant differences for dead calli (Table 1).

The obtained results showed that the hybrid Sc168 produced 267 alive calli while the other hybrid Sc10 produced 225. The number of dead calli was less in Sc168 (101) compared with Sc10 which was 109 (Figure 2B, 3 and 4). Genetic differences between two hybrids had a different response on the callus formation media.

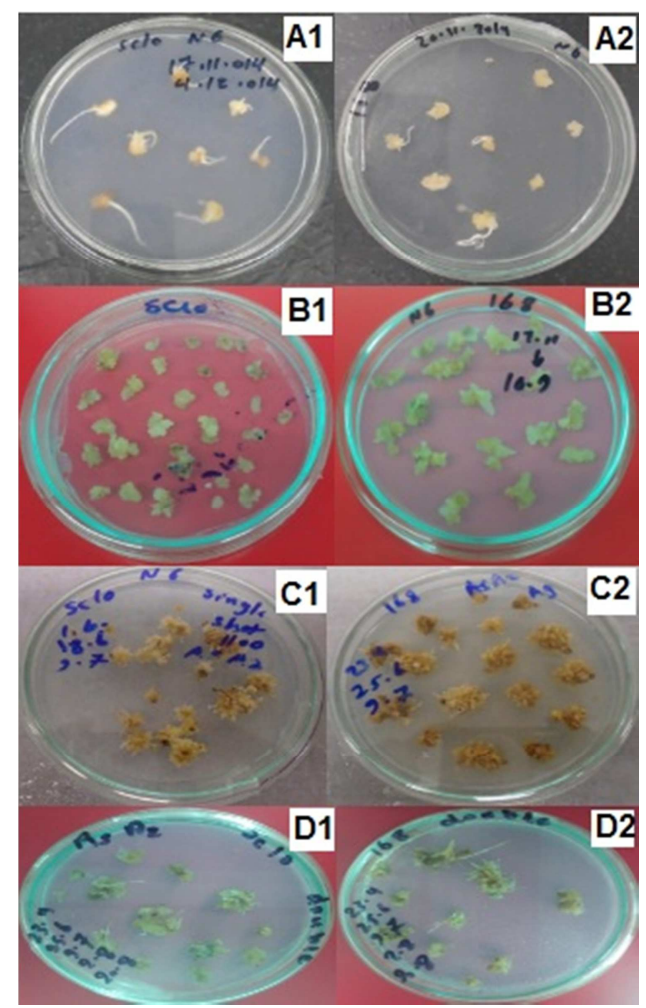

Figure 2. The different growth stages for embryo cultured on hybrids Sc10 and Sc168 as follow: A1, A2: planting of immature embryo for Sc10 and $S c 168$ respectively; $B 1, B 2$ : alive and dead callus; $C 1, C 2$ : calli on selection media; D1, D2: calli on regeneration media. 
Optimizing tissue culture protocols for maize is considered as the starting point for any genetic engineering program. It is important to detect the performance of plant genotypes on culture media in order to select the tissue culture media of high potential to plant regeneration in vitro. Maize genetic transformation basically determined by the capability of transformed tissues to proliferate and regenerate into whole plants [18]. Obtaining regenerated plant from the tissue culture of maize crop was reported earlier [19]. Existing efforts were made towards successful medium ingredients for explant regenerated into whole plant $[20,21]$ used a artificial medium for the generation and growth of monocotyledonous plants in vitro. Previous studies showed that immature embryos of maize and other cereals have been the preferred explant for in vitro culture and plant regeneration $[22,23]$.

Table 1. Analysis of variance for alive and dead calli under selection of two maize hybrids; Sc168 and Sc10.

\begin{tabular}{llll}
\hline \multirow{2}{*}{ S.O.V. } & \multirow{2}{*}{ D.F } & \multicolumn{2}{l}{ Mean of Squares } \\
\cline { 3 - 4 } & & Alive calli & Dead calli \\
\hline Hybrids & 1 & $48.80^{*}$ & $15.84 \mathrm{~ns}$ \\
Error & 80 & 10.55 & 20.05 \\
\hline
\end{tabular}

ns: not significant.

*: significant at level $(0.5)$

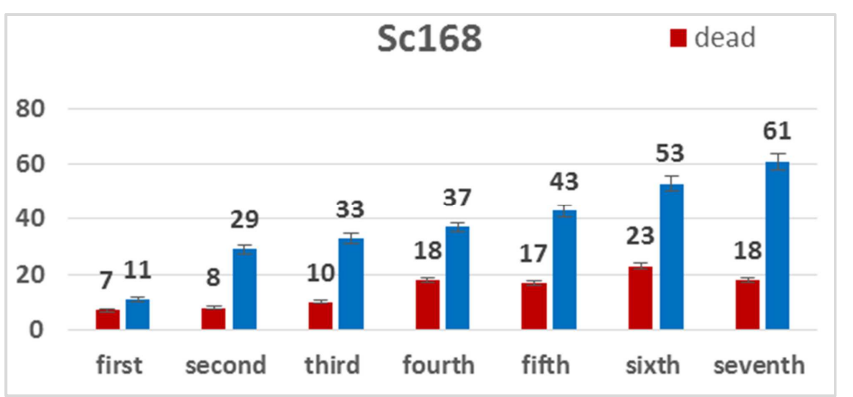

Figure 3. The number of alive and dead calli after seven sub culture before bombardment for variety sc168.

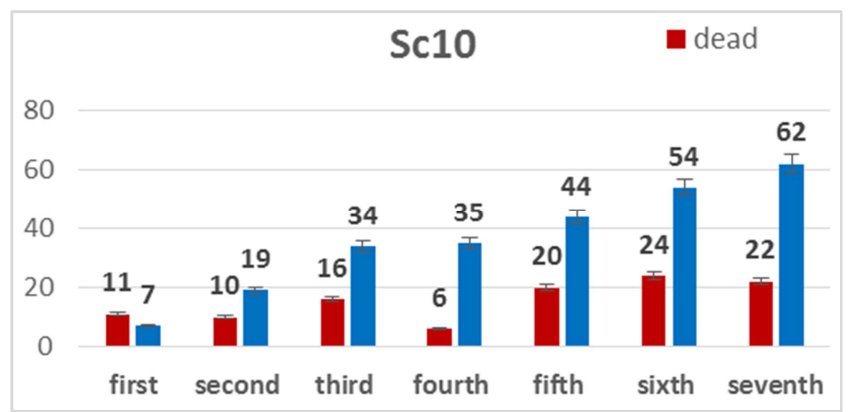

Figure 4. The number of alive and dead calli after seven sub culture before bombardment for variety sc10.

\subsection{Maize Genetic Transformation with Micro Projectile Bombardment}

A total of 32 plates containing maize somatic embryogenic calli type II were subjected to particle bombardment with a transformation vector C2ASA2-NOS-ASB (Figure 1). Single and double shot were used on embryogenic calli with 1100 psi. Calli of the two hybrids were transferred to selective medium with $100 \mu \mathrm{M} 6 \mathrm{MT}$ for selections as shown in Figure $2 \mathrm{C}$. Regarding response of calli under selection, calculation of dead and alive calli were performed every 21 days for four times. The number of alive calli were 133 and 63 in Sc168 and $\mathrm{Sc} 10$, respectively. On the other hand, dead calli were 123 in Sc168 and 70 in Sc10 (Figure 5 and 6). Calli On regeneration media of the two hybrids, Sc168 showed more regeneration efficiency than Sc10 (Figure 2D).

It is possible to introduce and express DNA stably in nearly 150 different plant species [24]. Microprojectile bombardment was reported to be the most suitable techniques for maize transformation $[25,26]$. Protocol improvement for maize transformation to increase the maize transformation efficiency and regeneration was performed [27]. It is important to highlight that transgenic maize tools has developed an important techniques to improve food and agronomic quality [28].

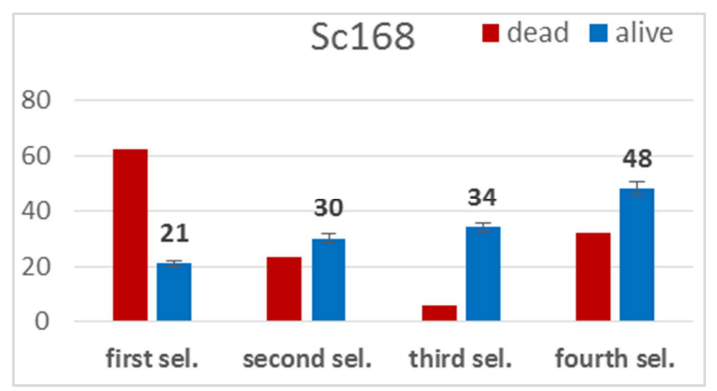

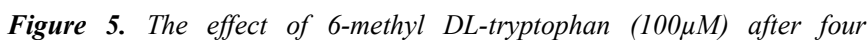
selections for variety Sc168.

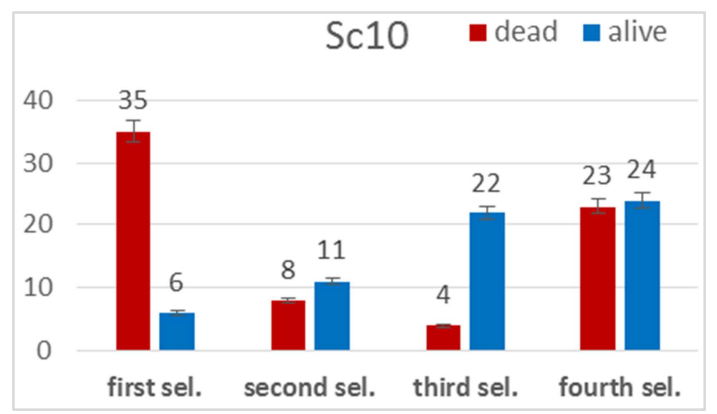

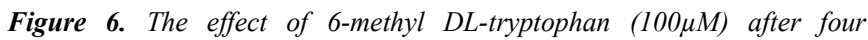
selections for variety $S c 10$.

\subsection{Transgenic Plants and Gus Activity}

Gus gene is selectable marker introduced into a cell in culture, that act as a trait appropriate for selection. In the present study the histochemical analysis was made in obtained calli. The GUS activity Gus expression was detected after $48 \mathrm{~h}$ in bombardment calli. The visualized blue spots were observed and photographed to confirm the insertion of the constructs (Figure 7). The degree of efficiency of Gus expression was higher in maize hybrid Sc 168 calli, which received double projectile shots at $1100 \mathrm{psi}(95 \%)$ than in calli in hybrid Sc10 subjected to only one shot (82\%). Within hybrid Sc10 calli subjected to double shots showed strong Gus expression than the single shot ones. The findings were with agreement with many authors [29-31]. 


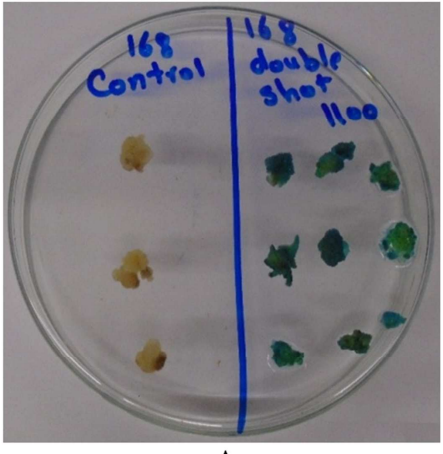

A

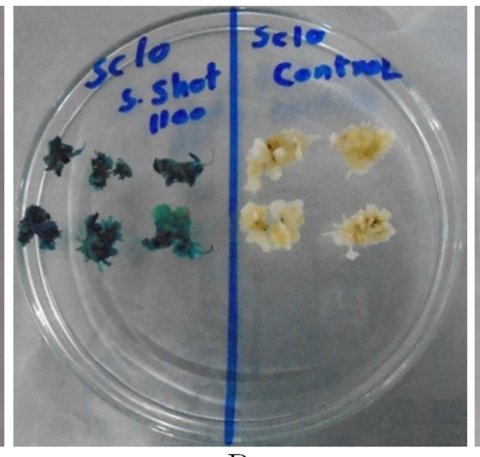

$\mathrm{B}$

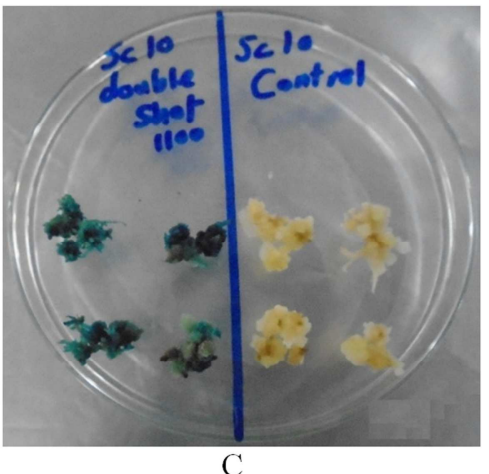

Figure 7. Strong $\beta$ - glucuronidase (GUS) expression A variety Sc168 double shot, B variety Sc10 single shot, C Sc10 double shot.

\subsection{Amino Acid Profile for Green Calli}

The green calli for two hybrids were tested for tryptophan content by amino acid analyzer. Green calli for hybrid Sc168 showed increase in the amount of tryptophan which were 29.210 for single shot and 29.309 for double shot respectively compared with hybrid Sc10 was 29.174 for single shot and 29.265 for double shot while control showed low level of tryptophan content with 29.162 (Table 2). Wakasa et al. [32] found high level of tryptophan in rice transgenic plants 143 nmol trp $\mathrm{g}^{-1}$ with AS gene $\alpha$-subunit compared with control was $33 \mathrm{nmol}$ trp $\mathrm{g}^{-1}$

Table 2. Tryptophan content in green calli for two Varieties.

\begin{tabular}{lll}
\hline Varieties & Single shot & Double shot \\
\hline Variety Sc168 & 29.210 & 29.309 \\
Variety Sc10 & 29.174 & 29.265 \\
Control & 29.162 & 29.162 \\
\hline
\end{tabular}

In the last few years, developments in genetic transformation technologies have made it possible to alter, modify and insert foreign genes at specific sites in chromosomes of the Zea maize [33-35]. Plant breeding programs needs to establish optimal tissue culture protocols for maize and other crops to assist genetic improvements using traditional and modern biotechnology tools.

\section{Conclusion}

Genetic differences in response to the tissue culture media and genetic transformation between the two studied maize hybrids were shown. For callus formation on induction media hybrid Sc168 produced more alive calli and less dead calli than the hybrid Sc10. Green calli for hybrid Sc168 showed increase in the amount of tryptophan using double shot compared with hybrid S10. Enhancing maize abiotic stress tolerance by taking the advantage of modern biotechnology tools such as genetic engineering and plant tissue culture are recommended in maize breeding programs.

\section{Acknowledgements}

This study was supported by a grant received from Science Technology Development Fund (2418) and Scientific
Research Academy.

\section{References}

[1] Faostat Agricultural database, Food and Agriculture Organization of the United Natios (FAO) http://www.fao.org/2009.

[2] Morgan, D. 2010. Egypt: growth and opportunity inagriculture. Available at: http://www.english.globalarabnetwork.com/201003155185/Ec onomics/growth-and-opportunity-in-egyptian-agriculture.html

[3] Snežana Mladenović Drinić, Dragana Ignjatović Micić, Iva Erić, Violeta anđ Elković, Dražen Jelovac, and Kosana Konstantinov. 2004. Biotechnology in maize breeding. Genetika, vol. 36, no. 2, 93-109, 2004.

[4] Abdel-Rahman M. M. and Widholm J. M. 2009. Transformation of two plasmids into maize callus using particle bombardment. Journal Enviromental Agriculture Science, Faculty of Agriculture Damanhour branch, Alexandria University. Vol. 8 (2) August.

[5] Shou H, Frame B. R., Witham S. A., and Wang K. 2004. Assessment of transgenic maize events produced by particle bombardment or Agrobacterium- mediated transformation Mol. Breeding 13: 201-208.

[6] USDA ERS 1999. Genetically engineered crops for pest management. U.S. Dept. of agriculture, economic research service, Washington, DC. http://www.ers.usda.gov/whatnew/issues/biotech

[7] Gordon-Kamm W. J., T. M. Spencer, M. L. Mangano, R. J. Adam S, N. G. Willets, T. B. Rice, C. J. Mackery, R. W. Krueger, A. P. Kaush, and P. G. Lemaux. 1990. Transformation of maize cells and regeneration of fertile transgenic plants. Plant Cell, 2, 603-618.

[8] Tsuji J., Zook M., Somerville S. C., Hammerschmidt L. 1993. Evidence that tryptophan is not a direct biosynthetic intermediate of camamexin in Arabidopsis thaliana Physiol.mol. Plant Pathol. 43: 221-229.

[9] Normanly J., Slovin J. P., Cohen J. D. 1995. Rethinking auxin biosynthesis and metabolism. Plant Physiol. 107: 323-329.

[10] Radwanski E. R., and LAST r.l. 1995. Tryptophan biosynthesis and metabolism: biochemicaland molecular genetics. Plant Cell 7: 921-934. 
[11] Rai. V. K. 2002. Role of amino acid in plant responses to stresses. Biol. Plantarum J., 45: 481-487.

[12] Zhao J, Last RL. 1996. Coordinate regulation of the tryptophan biosynthetic pathway and indolic phytoalexin accumulation in Arabidopsis. Plant Cel. 8: 2235-44; PMID: 8989880; http://dx.doi.org/10.1105/tpc.8.12.2235 [PMC free article, PubMed, Cross Ref].

[13] Kanno T, Kasai K, Ikejiri-Kanno Y, Wakasa K, Tozawa Y. 2004. In vitro reconstitution of rice anthranilate synthase: MAPK signaling pathways in plant abiotic stress responses. Mol Biol. 54: 11-22; http://dx.doi.org/10.1023/B:PLAN.0000028729.79034.07 [PubMed, Cross Ref].

[14] Chu CC, Wang CC, Sun CS, Hsu C, Yin KC, Chu CY and Bi F. 1975. Establishment of efficient medium for another culture of rice through comparative experiments on the nitrogen source. Sci. Sinica. 18: 659-668.

[15] Murashige T and Skoog F. 1962. Revised medium for rapid growth and bioassays with tobacco tissue cultures. Plant Physiol. 15: 473-479.

[16] Berardino MB., Roingeard F. C., Fukagawa N. K. 1990. Plasma tryptophan and tyrosine concentrations determination using high performance liquid chromatography and fluorometric detection J. Nutr. Biocheml. 220-222.

[17] Brotherton J. E., Schechter S., Ranch J. P., Widholm J. M. 1996. Inheritance and stability of 5 methyl tryptophan resistance in Dature innoxia selected in vitro Plant Cell Physiol. 37: 389-394.

[18] Valdez-ortiz A., Medina-godoy S., Evcerde M., Paredes-lo'pez O. 2007. Transgenic tropical maize line generated by the direct transformation of the embryo-scutellum by A. tumefaciens Plant cell tissue organ culture 9: 201-214.

[19] Green, C. E. and R. L. Phillips. 1975. Plant regeneration from tissue cultures of maize. Crop Sci., 15: 417-420.

[20] Straus, J. 1960. Maize endosperm tissue grown in vitro. III. Development of a synthetic medium. Am. J. Bot., 47: 641647.

[21] Schenk, R. U. and A. C. Hildebrandt. 1972. Medium and techniques for induction and growth of monocotyledonous and dicotyledonous plant cell cultures. Can. J. Bot., 50: 199-204.

[22] Armstrong CL, Green CE. 1985. Establishment and maintenance of friable, embryogenic maize callus and the involvement of L-proline. Planta. 164: 207-214.

[23] Ray DS, Ghosh PD. 1990. Somatic embryogenesis and plant regeneration from cultured leaf explants of Zea mays L. Ann.
Bot. 66: 497-500.

[24] Twyman R, Christou P, Stoger E (2002) Genetic transformation of plants and their cells, Molecular Biotechnology, John Innes Center, Norwich, United Kingdom pp. 126-150.

[25] Frame B, Zhang H, Cocciolone S, S idorenko L, Dietrich C, Pegg S, Zhen S, SchnableP, Wang K. 2000. Production of transgenic maize from bombarded type II callus: Effect of gold particle size and callus morphologyon transformation efficiency In Vitro Cell Dev. Biol. Plant 36: 21-29.

[26] Aulinger I, Peter S, Schmid J, Stamp P. 2003. Gametic embryos of maize as atarget for biolistic transformation: Comparison to immature zygotic embryos Plant Cell Rep. 21: 585-591.

[27] De'cima Oneto C, Bossio E, Gonza'lez G, Faccio P, Lewi D. 2010. High and low pressure gene gun devices gie similar transformation efficiencies in maize calluses Afr. J. Plant Sci 4 (7): $217-225$

[28] Oneto C. D., Gonzalez G., Lewi D. 2010. Biolistic maize transformation: Improving and simplifying the protocol efficiency Afr. J. of Agri Res. 25: 3561-3570.

[29] Gallagher SR. 1992. GUS protocols: using the GUS gene as a reporter of gene expression. Academic Press, New York.

[30] Jefferson RA. 1987 Assaying chimeric genes in plants: the GUS gene fusion system. Plant Mol. BioI. Rep. 5: 387-405.

[31] Jefferson RA, Kavanagh TA and Bevan MW. 1987. GUS fusion: f3-glucuronidase as a sensitive and versatile gene fusion marker in higher plants. EMBO J. 6: 3901-3907.

[32] Wakasa K., Tozawa Y., Terakawa T., Hasegawa H. 1999. Gene encoding $\alpha$-subunit of rice anthranilate synthase and DNA relating thereto. World Intellectual Property Organization 99/11800.

[33] Shukla V. K., Doyon, Y., Miller, J. C., Dekelver, R. C., Moehle, E. A., Worden, S. E., et al. 2009. Precise genome modification in the crop species (Zea mays L.) using zincfinger nucleases. Nature 459, 437-441.

[34] Gao H., Smith J., Yang M., Jones S., Djukanovic V., Nicholson M. G., et al. 2010. Heritable targeted mutagenesis in maize using a designed endonuclease. Plant J. 61: 176-187.

[35] Liang Z., Zhang K., Chen K., and Gao C. 2014. Targeted mutagenesis in maize (Zea mays L.) using TALENs and the CRISPR/Cas system J. Genet. Genomics 41: 63-68. 